\title{
Expression of microRNA 638 and sex-determining region Y-box 2 in hepatocellular carcinoma: Association between clinicopathological features and prognosis
}

\author{
WEIKANG YE, JIEKE LI, GUAN FANG, XIUPENG CAI, YAN ZHANG, \\ CHAOJUN ZHOU, LEI CHEN and WENJUN YANG \\ Department of General Surgery, The First Affiliated Hospital of Wenzhou Medical University, \\ Wenzhou, Zhejiang 325000, P.R. China
}

Received February 15, 2017; Accepted January 19, 2018

DOI: $10.3892 / \mathrm{ol} .2018 .8208$

\begin{abstract}
The aim of the present study was to determine the expression profile of microRNA 638 (miR-638) and sex-determining region Y-box 2 (SOX2) in hepatocellular carcinoma (HCC), and to investigate their association with clinicopathological features and survival. Reverse transcription-quantitative polymerase chain reaction analysis was used to investigate miR-638 and SOX2 expression in 78 patients with HCC. Western blot and immunohistochemical analyses were performed in order to determine SOX2 protein expression in HCC samples. Combined with the clinical postoperative follow-up data, the expression of miR-638 and SOX2 and the association between this and the prognostic values of patients with HCC were statistically analyzed. The results of the present study confirmed that miR-638 expression in tumor tissues was significantly downregulated $(\mathrm{P}<0.001)$, while SOX 2 expression was significantly increased, compared with healthy control tissues $(\mathrm{P}<0.05)$. In addition, a significant inverse correlation between miR-638 and SOX2 expression was also observed in the HCC tissues $(\mathrm{r}=-0.675 ; \mathrm{P}<0.05)$. Clinicopathological correlation analysis demonstrated that reduced miR-638 and elevated SOX2 expression was significantly associated with the Tumor-Node-Metastasis stage and portal vascular invasion $(\mathrm{P}<0.05)$. However, no significant differences were observed in other clinicopathological features, including age, sex, tumor size, tumor differentiation and hepatitis status $(\mathrm{P}>0.05)$. Notably, follow-up analysis revealed that patients with HCC with low miR-638 expression and high SOX2 expression tended to have a significantly shorter postoperative survival time $(\mathrm{P}<0.001)$. It was concluded that miR-638 may serve
\end{abstract}

Correspondence to: Professor Wenjun Yang, Department of General Surgery, The First Affiliated Hospital of Wenzhou Medical University, 2 Fuxue Lane, Wenzhou, Zhejiang 325000, P.R. China E-mail: yangwenjun_doc@163.com

Key words: hepatocellular carcinoma, microRNA 638, sex-determining region Y-box 2, prognosis a vital role in the occurrence and progression of $\mathrm{HCC}$ by regulating SOX2 expression and thus, that miR-638 and SOX2 may be critical as novel diagnostic and prognostic biomarkers for HCC.

\section{Introduction}

Hepatocellular carcinoma (HCC) has one of the highest cancer-associated mortality rates worldwide, with a higher incidence observed more frequently in males than females (1). Although the prognosis for HCC has improved during the last two decades, HCC remains the sixth most common type of cancer globally and the second leading cause of cancer-associated mortality among males globally, with China alone accounting for $\sim 50 \%$ of the total number of cases and mortalities (1). The traditional treatment method for HCC is surgery, including partial hepatectomy, transarterial chemoembolization and liver transplantation, followed by systemic postoperative chemotherapy; however, its clinical benefits remain uncertain (2-4). As the majority of patients with $\mathrm{HCC}$ are diagnosed at an advanced stage, with lymphatic or hematogenous metastasis to distal organs, curative surgical treatment at this time is no longer beneficial (5). Consequently, it is an ongoing effort to identify the metastatic behavior of HCC in clinical studies and the specific molecular biomarkers that may serve as potential diagnostic and prognostic indicators.

MicroRNAs (miRNAs/miRs) are a small class of endogenous non-coding RNAs (length, 19-22 nucleotides) that regulate the expression of protein-coding genes. In general, miRNAs suppress mRNA translation or degradation by binding to the $3^{\prime}$-untranslated region (3'-UTR) of target mRNAs (6). Numerous studies have demonstrated that miRNAs serve pivotal regulatory functions in cell cycle control (7), proliferation (8), differentiation (9), metastasis (10) and carcinogenesis (11). In human cancer, it has been observed that miRNAs function as tumor oncogenes or suppressor genes in the occurrence and progression of tumors $(12,13)$. Dysregulation of miR-638 has been reported in several different types of cancer. For example, miR-638 has been demonstrated to be involved in colorectal carcinoma (14), gastric cancer (15), breast cancer (16) and osteosarcoma (17), 
through dysregulation of its target genes as a tumor suppressor. Furthermore, miR-638 has also been demonstrated to promote melanoma progression and metastasis by suppressing tumor protein p53-mediated apoptosis pathways and autophagy as an oncogene (18). These inconsistent observations suggested that the function of miR-638 in tumorigenesis is cancer-specific.

The sex-determining region Y (SRY)-box 2 (SOX2) gene is a key transcriptional regulator associated with the maintenance of cell pluripotency and self-renewal in embryonic stem cells, encoding a member of the SRY-associated high mobility group (HMG)-box (SOX) family of transcription factors (19). Over time, accumulating evidence has established that the pro-oncogenic roles of SOX2 vary among different types of human malignant tumors, including breast (20), colorectal (21), prostate (22) and lung cancer (23). However, there has been contradictory evidence regarding SOX 2 in certain types of tumor, with a number of studies suggesting that SOX2 may suppress tumors and that increased SOX2 expression inhibits cell proliferation and metastasis (24-26). In line with this, several studies have reported that miR-638 suppressed cell invasion, proliferation and epithelial-mesenchymal transition by downregulating SOX 2 gene expression in non-small cell lung cancer (NSCLC) and colorectal carcinoma cells $(27,28)$. As for $\mathrm{HCC}$, there are limited studies that have investigated miR-638 and SOX2 expression and the clinical significance of this $(29,30)$. Notably, whether or not an association exists between these two molecules remains to be elucidated.

The aim of the present study was to investigate miR-638 and SOX2 expression in human HCC tissues and their matched non-cancerous tissues, and to assess their association with clinicopathological features. The results of the present study demonstrated that miR-638 was downregulated and that SOX2 was upregulated in HCC, with a significant inverse correlation. Furthermore, reduced miR-638 expression and elevated SOX2 expression was associated with tumor stage, portal vascular invasion and poor postoperative survival. Consequently, they may be regarded as potential biomarkers for predicting HCC progression and prognosis.

\section{Materials and methods}

Clinical specimens and follow-up data. A total of 78 fresh cancerous tissues and their matched adjacent non-cancerous controls ( $\geq 3 \mathrm{~cm}$ from the tumor margin) were obtained from patients with HCC who had undergone routine curative surgical removal of the tumor at The First Affiliated Hospital of Wenzhou Medical University (Zhejiang, China) between January 2011 and July 2012. The histological diagnoses of the HCC specimens were independently confirmed by two senior pathologists at the First Affiliated Hospital of Wenzhou Medical University (Wenzhou, China), and the relevant clinicopathological information and follow-up data were retrieved from patient hospital records. Some of the surgically resected specimens were stored in liquid nitrogen at $-80^{\circ} \mathrm{C}$ for further reverse transcription-quantitative polymerase chain reaction (RT-qPCR) or western blot analysis. The remaining specimens were fixed in a fixation solution containing $4 \%$ paraformaldehyde for $24 \mathrm{~h}$ at $4^{\circ} \mathrm{C}$ and were embedded in paraffin blocks for immunohistochemical analysis. Ethical approval was obtained from the Ethics Committee of The First Affiliated Hospital of
Wenzhou Medical University, and written informed consent was obtained from all patients. Clinical specimens were collected from 67 males and 11 females aged between 30 and 83 years (mean, 57 years). Tumor size was classified according to the maximum size of the tumor detected by magnetic resonance imaging. Tumors were staged between I and IV, according to the latest edition of Tumor-Node-Metastasis (TNM) classification system of the American Joint Committee Cancer and Union for International Cancer Control (31). Tumor differentiation was assigned using the World Health Organization classification and grading system $(32,33)$. The detailed clinicopathological data regarding the specimens are summarized in Table I.

$R T-q P C R$. Total RNA was extracted from tumor tissues and adjacent non-cancerous tissues using the E.Z.N.A miRNA kit (Omega Bio-Tek, Inc., Norcross, GA, USA), according to the manufacturer's protocol. miRNA expression analysis, synthesis of first strand cDNA and RT-qPCR were performed using the All-in-One ${ }^{\mathrm{TM}}$ miR RT-qPCR detection kit (GeneCopoeia, Inc., Rockville, MD, USA), according to the manufacturer's protocol. The reverse transcriptase reaction mixture $(25 \mu \mathrm{l})$, containing $2 \mu \mathrm{g}$ total RNA, was applied by incubating mixtures at $37^{\circ} \mathrm{C}$ for $60 \mathrm{~min}, 85^{\circ} \mathrm{C}$ for $5 \mathrm{~min}$, and $4^{\circ} \mathrm{C}$ for $30 \mathrm{~min}$. The $20 \mu \mathrm{l}$ PCR reaction mixture contained $1.2 \mu \mathrm{l}$ RT product, $10 \mu \mathrm{l} 2 \mathrm{x}$ All-in-One qPCR Master mix, $2 \mu \mathrm{l}$ of each primer and $4.8 \mu \mathrm{l} \mathrm{ddH_{2 }} \mathrm{O}$. The primer sequences for miR-638 (cat. no. HmiR0295) and the reference gene small nuceloular RNA, C/D box 44 (RNU44; cat. no. HmiRQP9011) were designed and purchased from GeneCopoeia Inc. Following an initial denaturation step at $95^{\circ} \mathrm{C}$ for $10 \mathrm{~min}$, the PCR samples were run for 40 cycles of $95^{\circ} \mathrm{C}$ for $10 \mathrm{sec}, 60^{\circ} \mathrm{C}$ for $20 \mathrm{sec}$ and $72^{\circ} \mathrm{C}$ for $10 \mathrm{sec}$. The relative expression of miR- 638 was calculated using the $2^{-\Delta \Delta \mathrm{Cq}}$ method (34), based upon the quantification cycle $(\mathrm{Cq})$ method with RNU44 small nuclear RNA molecule as an endogenous reference.

For the measurement and quantification of SOX 2 mRNA, cDNA was synthesized using the Hiscript ${ }^{\circledR}$ Q RT SuperMix for qPCR (Vazyme, Piscataway, NJ, USA). The PCR reaction (20 $\mu \mathrm{l}$ ) contained $2 \mu \mathrm{l}$ reverse transcriptase product, $10 \mu \mathrm{l}$ AceQ ${ }^{\circledR}$ qPCR SYBR ${ }^{\circledR}$-Green Master mix (Vazyme), and $0.4 \mu \mathrm{l}$ of each primer. The PCR samples were subsequently incubated at $95^{\circ} \mathrm{C}$ for $3 \mathrm{~min}$, followed by 49 cycles at $95^{\circ} \mathrm{C}$ for $15 \mathrm{sec}, 60^{\circ} \mathrm{C}$ for $1 \mathrm{~min}$ and $50^{\circ} \mathrm{C}$ for $30 \mathrm{sec}$. Relative expression levels of SOX 2 were calculated based on the $2^{-\Delta \Delta \mathrm{Cq}}$ method and GAPDH was used as an internal control. All PCR analyses were performed using a CFX96 ${ }^{\mathrm{TM}}$ Real-Time PCR detection system (Bio-Rad Laboratories, Inc., Hercules, CA, USA).

The primers for SOX2 and GAPDH were as follows: SOX2 forward, 5'-CGAGATAAACATGGCAATCAAAAT-3'; and reverse, 5'-AATTCAGCAAGAAGCCTCTCCTT-3'; GAPDH forward, 5'-TGCACCACCAACTGCTTAGC-3' and reverse, 5'-GGCATGGACTGTGGTCATGAG-3'. The primer sequences for miR-638 (cat. no. HmiR0295) and RNU44 (cat. no. HmiRQP9011) were purchased from GeneCopoeia Inc.

Immunohistochemistry (IHC) and assessment of IHC. Briefly, paraffin-embedded tissue blocks were sectioned (5 $\mu \mathrm{m}$ thick) using a microtome, transferred onto tissue anti-off slides and heated at $60^{\circ} \mathrm{C}$ for $4 \mathrm{~h}$. Tissue sections were dewaxed with 
Table I. Association between miR-638 or SOX2 expression and clinicopathological characteristics in 78 patients with hepatocellular carcinoma.

\begin{tabular}{|c|c|c|c|c|c|c|c|}
\hline \multirow[b]{2}{*}{ Variable } & \multicolumn{4}{|c|}{ Expression of miR-638 } & \multicolumn{3}{|c|}{ Expression of SOX2 } \\
\hline & $\mathrm{n}=78$ & $\begin{array}{c}\text { Low } \\
(n=39)\end{array}$ & $\begin{array}{l}\text { High } \\
(\mathrm{n}=39)\end{array}$ & P-value & $\begin{array}{l}\text { Negative } \\
(n=33)\end{array}$ & $\begin{array}{c}\text { Positive } \\
(\mathrm{n}=45)\end{array}$ & P-value \\
\hline Age, years & & & & 0.820 & & & 0.710 \\
\hline$<57$ & 35 & 17 & 18 & & 14 & 21 & \\
\hline$\geq 57$ & 43 & 22 & 21 & & 19 & 24 & \\
\hline Sex & & & & 0.104 & & & 0.188 \\
\hline Male & 67 & 36 & 31 & & 26 & 41 & \\
\hline Female & 11 & 3 & 8 & & 7 & 4 & \\
\hline Tumor size, $\mathrm{cm}$ & & & & 0.712 & & & $0.009^{b}$ \\
\hline$<5$ & 51 & 23 & 28 & & 27 & 24 & \\
\hline$\geq 5$ & 27 & 11 & 16 & & 6 & 21 & \\
\hline Tumor number & & & & 0.711 & & & 0.456 \\
\hline 1 & 70 & 34 & 36 & & 31 & 39 & \\
\hline$\geq 2$ & 8 & 5 & 3 & & 2 & 6 & \\
\hline Hepatitis B virus & & & & 0.411 & & & 0.224 \\
\hline Positive & 61 & 29 & 32 & & 28 & 33 & \\
\hline Negative & 17 & 10 & 7 & & 5 & 12 & \\
\hline Cirrhosis & & & & 0.745 & & & 0.751 \\
\hline Yes & 67 & 34 & 33 & & 29 & 38 & \\
\hline No & 11 & 5 & 6 & & 4 & 7 & \\
\hline AFP & & & & 0.784 & & & 0.915 \\
\hline$<400 \mathrm{ng} / \mathrm{ml}$ & 61 & 31 & 30 & & 26 & 35 & \\
\hline$\geq 400 \mathrm{ng} / \mathrm{ml}$ & 17 & 8 & 9 & & 7 & 10 & \\
\hline Tumor differentiation & & & & 0.751 & & & 0.675 \\
\hline Well & 31 & 16 & 15 & & 15 & 16 & \\
\hline Moderately & 31 & 14 & 17 & & 12 & 19 & \\
\hline Poorly & 16 & 9 & 7 & & 6 & 10 & \\
\hline TNM stage & & & & $0.001^{\mathrm{b}}$ & & & $0.002^{\mathrm{b}}$ \\
\hline I-II & 48 & 17 & 31 & & 27 & 21 & \\
\hline III-IV & 30 & 22 & 8 & & 6 & 24 & \\
\hline Portal vascular invasion & & & & $0.005^{\mathrm{b}}$ & & & $0.012^{\mathrm{a}}$ \\
\hline Yes & 21 & 16 & 5 & & 4 & 17 & \\
\hline No & 57 & 23 & 34 & & 29 & 28 & \\
\hline Distant metastasis & & & & 0.156 & & & 0.071 \\
\hline Yes & 9 & 7 & 2 & & 1 & 8 & \\
\hline No & 69 & 32 & 37 & & 32 & 37 & \\
\hline
\end{tabular}

${ }^{\mathrm{a}} \mathrm{P}<0.05,{ }^{\mathrm{b}} \mathrm{P}<0.01$. miR, microRNA; SOX2, sex-determining region Y-box 2; AFP, $\alpha$-fetoprotein; TNM, Tumor-Node-Metastasis.

dimethylbenzene and rehydrated in a descending ethanol series $(100,95,85$ and $75 \%)$. Endogenous peroxidase activity was blocked with $0.3 \%$ hydrogen peroxide for $10 \mathrm{~min}$ at room temperature, and the sections were subsequently boiled by microwave in $0.01 \mathrm{~mol} / \mathrm{l}$ citrate antigen retrieval solution ( $\mathrm{pH} 6.0$ ) for $15 \mathrm{~min}$ at $100^{\circ} \mathrm{C}$. Following 3 washes with phosphate-buffered saline, the sections were blocked with $10 \%$ goat serum (cat. no C0265; Beyotime Institute of Biotechnology, Haimen, China) in phosphate-buffered saline (PBS) for $15 \mathrm{~min}$ at $37^{\circ} \mathrm{C}$, and incubated with a rabbit anti-human SOX2 polyconal antibody (dilution, 1:200; cat. no. ab97959; Abcam, Cambridge, UK) in a humidified chamber overnight at $4^{\circ} \mathrm{C}$. The sections were subsequently incubated with a horseradish peroxidase (HRP)-labeled goat anti-rabbit secondary antibody (dilution, 1:100; cat. no. pv-6001; OriGene Technologies, Inc., Rockville, MD, USA) for $30 \mathrm{~min}$ at $37^{\circ} \mathrm{C}$ and washed with PBS to remove excess antibody. The sections were stained with 3,3'-Diaminobenzidine tetrahydrochloride 
for $1 \mathrm{~min}$ at room temperature and observed using an optical microscope at a magnification, $x 40$. Finally, the sections were counterstained with hematoxylin (OriGene Technologies, Inc.) for $3 \mathrm{~min}$ at room temperature, dehydrated, cleared, mounted and examined. In the present study, a PBS-only stained liver sample was used as a negative control, and human gastric cancer tissue was used as a positive control.

Semi-quantitative analysis. SOX2 expression in tumor tissues was semi-quantitatively evaluated and scored on the basis of the staining extent of positively stained cells, as described previously by Chen et al (24). Only nuclei stained brown were defined as SOX2-positive. For all samples, the staining intensity and percentage of positive tumor cells were evaluated and classified under double-blind conditions. Briefly, the staining intensities were scored as follows: 0, negative staining; 1 , weak staining; 2 , medium staining; or 3 , strong staining. The staining percentage score (positively-stained cells/total tumor cells x100\%) was defined as follows: 0,$0 ; 1,1-9 ; 2,10-29 ; 3$, 30-49; or 4, 50-100\%. Consequently, a final semi-quantitative immunoreactivity score (IRS) of SOX2 staining was obtained by multiplying the staining percentage score by the staining intensity score, resulting in scores ranging between 0 and 12 . For statistical analyses, tumors with a final IRS of $<5$ were categorized as a low protein expression group and those with a final IRS of $\geq 6$ were categorized as a high protein expression group.

Western blot analysis. The cancerous liver tissue samples and their adjacent non-cancerous tissue samples were homogenized using a radioimmunoprecipitation acid lysis buffer kit (Beyotime Institute of Biotechnology), and the lysates were subsequently centrifuged at $13,400 \mathrm{x}$ g for $15 \mathrm{~min}$ at $4^{\circ} \mathrm{C}$. The total protein concentration was measured by using the BCA method (Beyotime Institute of Biotechnology). Protein samples (40 $\mu \mathrm{g}$ of each sample) were separated by $12 \%$ SDS-PAGE, prior to being transferred onto polyvinylidene difluoride membranes. Following blocking with 5\% skimmed milk buffer for $120 \mathrm{~min}$ at room temperature, the membrane was incubated with anti-SOX2 (dilution, 1:2,000; cat. no. ab97957; Abcam, Cambridge, UK) and GAPDH (dilution, 1:2,000; cat. no. 5174; Cell Signaling Technology, Inc., Danvers, MA, USA) primary antibodies overnight at $4^{\circ} \mathrm{C}$. Following three washes with $0.1 \%$ TBST for 5 min each time, the membranes were incubated with a HRP-conjugated goat anti-rabbit IgG secondary antibody (dilution, 1:5,000; cat. no 774P2; Cell Signaling Technology, Inc.) for $2 \mathrm{~h}$ at room temperature, prior to being washed again with $0.1 \%$ TBST 3 times. Finally, the protein complexes on the band were detected using a SuperSignal Western Femto kit (Pierce; Thermo Fisher Scientific, Inc., Waltham, MA, USA), and were subsequently quantified using the ChemiDoc XRS ${ }^{+}$system with Image $\mathrm{Lab}^{\text {TM }}$ 3.0 Software (cat. no. 1708265; Bio-Rad Laboratories, Inc.).

Statistical analysis. Data are presented as the mean \pm standard deviation, and were analyzed using SPSS 20.0 software (IBM Corp., Armonk, NY, USA) and GraphPad Prism 5.01 statistical software (GraphPad Software, Inc., La Jolla, CA, USA). The Pearson $\chi^{2}$ and Fisher's exact tests were performed in order to test the significance of observed clinicopathological variables among different groups. Student's t-test was performed to compare the miR-638 and SOX2 expression levels between different groups. Comparisons among multiple groups were performed using one-way analysis of variance and a Tukey's test. The association between miR-638 and SOX 2 in the matched HCC tumor specimens was determined using Pearson's correlation analysis, and r-values represent the Pearson's correlation coefficient. The Kaplan-Meier method, followed by the log-rank test, and Cox proportional hazards regression model analysis were performed in order to plot survival curves and to calculate the hazard ratios (HRs) and the $95 \%$ confidence intervals (CIs), respectively. $\mathrm{P}<0.05$ was considered to indicate a statistically significant difference.

\section{Results}

Patient characteristics. With regards to tumor size, 51 cases $(65.4 \%)$ were classified as small $(<5 \mathrm{~cm}$ in maximum diameter) and 27 cases $(34.6 \%)$ were classified as large $(\geq 5 \mathrm{~cm}$ in maximum diameter). With respect to tumor grades, 31 cases $(39.7 \%)$ were categorized as well-differentiated, 31 cases $(39.7 \%)$ as moderately-differentiated, and 16 cases $(20.6 \%)$ as poorly-differentiated (Table I). In terms of clinical TNM stage, 48 cases $(61.5 \%)$ exhibited TNM stage I-II disease and 30 cases $(38.5 \%)$ exhibited TNM stage III-IV disease. With regards to tumor vascular invasion, 21 cases $(26.9 \%)$ exhibited portal vascular invasion and 57 cases $(73.1 \%)$ exhibited no vascular invasion (Table I). There were 61 cases $(78.2 \%)$ of hepatitis B (HBV) positivity and 9 cases $(11.5 \%)$ of distant metastasis. The overall survival period was defined as the time period between the date of surgical resection of HCC to the last follow-up or patient mortality. Mortalities caused by other events were considered to be censored (Table I).

Expression of miR-638 and SOX2 mRNA in human HCC. To assess miR-638 and SOX2 expression in HCC tumor tissues and paired adjacent normal tissues, RT-qPCR was performed. In the present study, it was demonstrated that miR-638 expression in tumor tissues was significantly lower than that in paired pericancerous healthy tissues (Fig. 1A; P<0.001). However, SOX2 mRNA expression was significantly upregulated (Fig. 1B; $\mathrm{P}<0.001)$. Furthermore, miR-638 expression in HCC tissues were negatively correlated with that of SOX2 mRNA ( $r=-0.675$; Fig. 1C; $\mathrm{P}<0.001)$. The median expression of miR-638 and SOX2 were used as cut-off points to divide 78 samples into two groups. For statistical analysis, samples with miR-638 expression levels equal to or above the cut-off point were categorized as the high expression group $(n=39)$ and samples with miR-638 expression levels below the cut-off point were categorized as the low expression group $(n=39)$.

SOX2 protein expression is inversely associated with $\mathrm{miR}-638$ expression. In order to study the association between miR-638 and SOX2 protein in HCC, SOX2 protein levels were measured in 78 pairs of tumor tissues and their adjacent non-cancerous tissues using western blot and immunohistochemical analyses. Western blot analysis demonstrated that SOX2 protein levels were significantly increased in 15 paired HCC samples, compared with adjacent non-cancerous samples (Fig. 2A; $\mathrm{P}<0.001)$. Immunohistochemical staining results revealed 
A

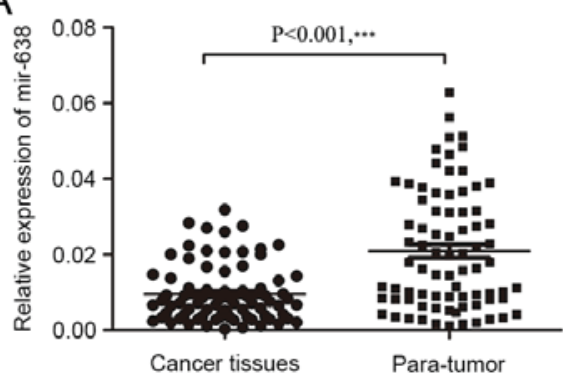

B

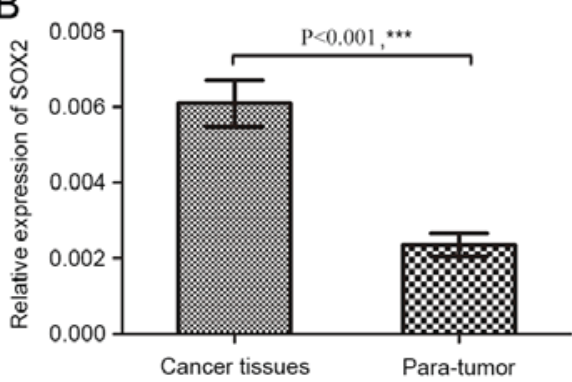

C

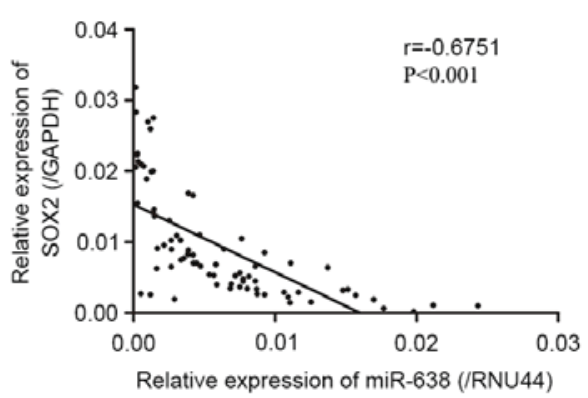

Figure 1. miR-638 is downregulated and SOX2 is overexpressed in patients with HCC. (A) miR-638 mRNA expression in 78 pairs of human HCC tissues and corresponding para-tumor tissues. (B) SOX2 mRNA expression in cancer tissues and para-tumor tissues was examined by reverse transcription-quantitative polymerase chain reaction $(\mathrm{P}<0.05)$. (C) An inverse correlation was observed between miR-638 and SOX2 mRNA expression levels in HCC tissues ( $\mathrm{r}=-0.675$; $\mathrm{P}<0.001) .{ }^{* *} \mathrm{P}<0.05,{ }^{* * *} \mathrm{P}<0.001$. miR, microRNA; SOX2, sex-determining region Y-box 2; HCC, hepatocellular carcinoma; para-tumor, paracancerous tissues.
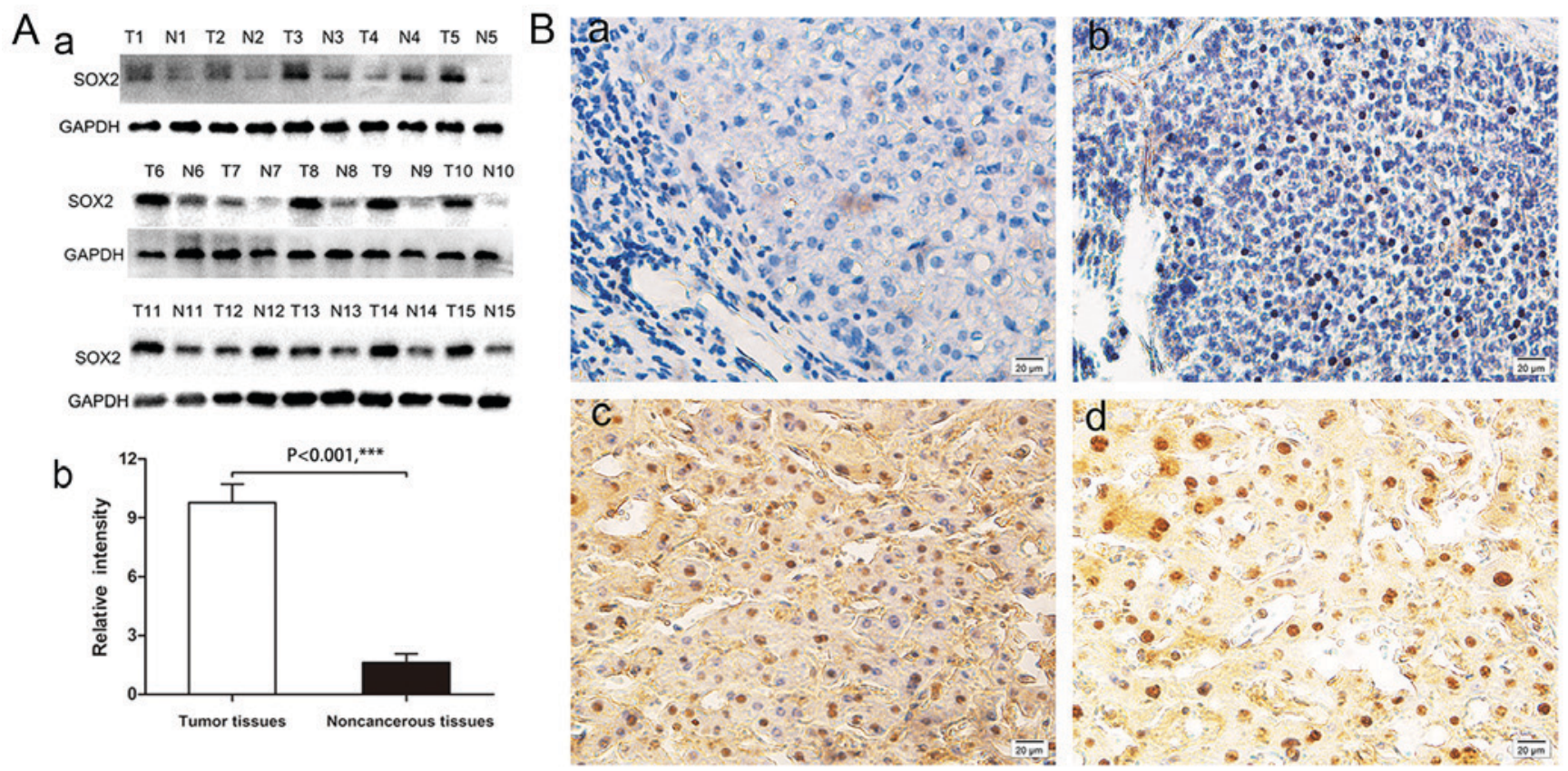

C a

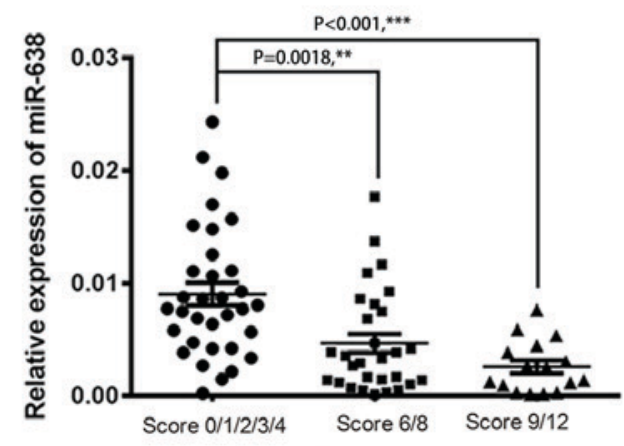

IRS of SOX2 staining b

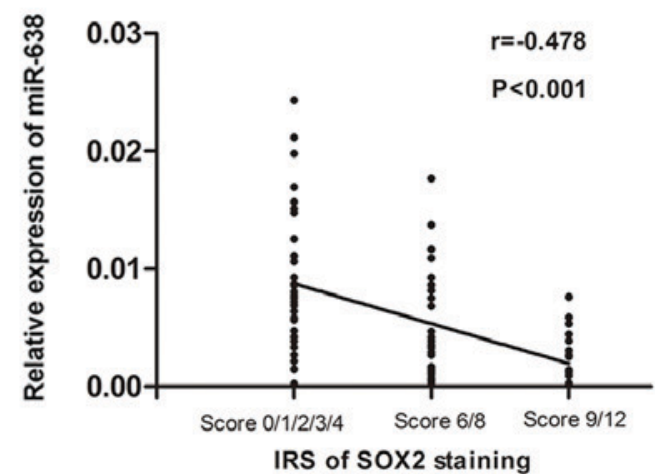

Figure 2. SOX2 was overexpressed in HCC tissues. (A) Expression of a) SOX2 protein in HCC tissues and matched adjacent non-cancerous tissues in 15 randomly selected patients with HCC was detected by b) western blot analysis. (B) Representative images of immunohistochemical staining of SOX2 in HCC tissues and adjacent non-cancerous tissues are presented in a-d. (Ba) No staining was detected for SOX2 in the blank control group; (Bb) weak nuclear staining of SOX2 in tumor cells; (Bc) medium nuclear staining of SOX2 in tumor cells; and (Bd) strong nuclear staining of SOX2 in tumor cells. (C) The a) semi-quantitative IRS of SOX2 staining was b) negatively correlated with the miR-638 levels in HCC tissues (one-way analysis of variance, $\mathrm{P}<0.05 ;$ Spearman's, $\mathrm{r}=-0.478 ; \mathrm{P}<0.001$ ). ${ }^{* *} \mathrm{P}<0.05,{ }^{* * *} \mathrm{P}<0.001 . S O X 2$, sex-determining region Y-box 2; HCC, hepatocellular carcinoma; IRS, immunoreactivity score; miR, microRNA.

that SOX2-positive staining was only evident in the nuclei of tumor cells but not in peritumoral tissues. The representative images of SOX2 immunostaining in HCC tissues are presented in Fig. 2B. Of the 78 samples, 45 (57.7\%) displayed high expression of SOX 2 in tumor tissues compared with $21(26.9 \%)$ paracancerous tissues samples exhibiting high 
Table II. Expression of SOX2 in HCC tissues and paracancerous tissues.

\begin{tabular}{lcccccr}
\hline & & \multicolumn{4}{c}{ Expression of SOX2 } \\
\cline { 3 - 6 } Group & Total & Negative & Positive & Positive rate (\%) & $\chi^{2}$ & P-value \\
\hline HCC tissues & 78 & 33 & 45 & 57.7 & 15.127 & 0.000 \\
Paracancerous tissues & 78 & 57 & 21 & 26.9 & & \\
\hline
\end{tabular}

SOX2, sex-determining region Y-box 2; HCC, hepatocellular carcinoma.

Table III. The association between miR-638 and the IRS of SOX2 staining expression in 78 pairs of hepatocellular carcinoma samples.

\begin{tabular}{lcccccr}
\hline & \multicolumn{3}{c}{ IRS } & & \\
nyoup & $0 / 1 / 2 / 3 / 4$ & $6 / 8$ & $9 / 12$ & Total & $\chi^{2}$ & P-value \\
\hline miR-638 expression & 8 & 19 & 12 & 39 & 15.551 & 0.000 \\
High & 25 & 10 & 4 & 39 & & \\
Low & 33 & 29 & 16 & 78 & & \\
Total & & & & & \\
\hline
\end{tabular}

miR, microRNA; IRS, immunoreactivity score; SOX2, sex-determining region Y-box 2.

expression $\left(\chi^{2}=15.127\right.$, Table II; $\left.\mathrm{P}<0.001\right)$. Furthermore, in order to statistically analyze the correlation between miR-638 and SOX2, a cross analysis was performed and is presented in Table III $\left(\chi^{2}=15.551 ; \mathrm{P}<0.0001\right)$, and the results revealed that the semi-quantitative immunoreactivity scores (IRS) of SOX2 staining in HCC tissues were negatively associated with miR-638 expression level (one-way analysis of variance, $\mathrm{P}<0.05 ; \mathrm{r}=-0.478, \mathrm{P}<0.001$; Fig. 2C). The aforementioned results indicated that increased SOX2 expression in HCC may be due to miR-638 underexpression, suggesting a potential functional link between these two molecules.

Correlation between miR-638 or SOX2 expression and clinicopathological features. To observe whether miR-638 and SOX2 expression levels were correlated with clinicopathological features of HCC, clinicopathological analysis was performed (Table I). The data indicated that miR-638 and SOX2 were not significantly correlated with age, sex, tumor size, tumor number, serum a-fetoprotein (AFP) level, tumor differentiation (all $\mathrm{P}>0.05$ ). By contrast, a significant association was observed between miR-638 or SOX2 expression and TNM staging ( $\mathrm{P}=0.001$ and 0.002 , respectively). It was also demonstrated that patients with $\mathrm{HCC}$ with lower miR-638 expression and higher SOX2 expression were more likely to be at a higher portal vascular rate $(\mathrm{P}=0.005$ and 0.012 , respectively). The results from the present study suggested that miR-638 and SOX2 expression may serve a vital role in HCC progression and may have potential as novel prognosis biomarkers for HCC.

Association between miR-638 or SOX2 expression and the prognosis of patients with HCC. In order to further evaluate whether there was an association between miR-638 or SOX2 expression and the overall prognosis of patients with HCC, the Kaplan-Meier method and Cox regression analysis were performed. Kaplan-Meier survival analysis suggested that miR-638 expression was significantly associated with a higher overall survival rate [median survival time (determined from the date of operation to the last visit or death), 50.20 vs. 19.10 months; Fig. 3A; $\mathrm{P}<0.001]$. Consistently, the overall survival rate of patients with exhibiting SOX2-positive expression was significantly lower than in those with SOX2-negative expression (median survival time, 19.80 vs. 50.75 months; Fig. 3B; $\mathrm{P}<0.001)$. Furthermore, Univariate Cox proportional hazards regression model analysis demonstrated that tumor size, tumor number, HBV status, TNM stage, portal vascular invasion, distant metastasis, and miR-638 and SOX2 expression were statistically significant risk factors for the overall survival of patients with HCC (Table IV). However, age, sex, cirrhosis, serum AFP level and tumor differentiation had no prognostic value. Multivariate analysis, stratified for the known prognostic variables, revealed that portal vascular invasion $(\mathrm{P}=0.029)$, expression of SOX2 $(\mathrm{P}=0.013)$ and expression of miR-638 $(\mathrm{P}=0.008)$ were independent prognostic factors of HCC. These observations suggested that miR-638 and SOX2 may serve as novel prognostic biomarkers for patients diagnosed with HCC.

\section{Discussion}

HCC remains one of the leading causes of cancer-associated mortality worldwide (1). Due to the fact that there are no effective methods for prevention or early diagnosis, the lack of effective treatment strategies means that patients 

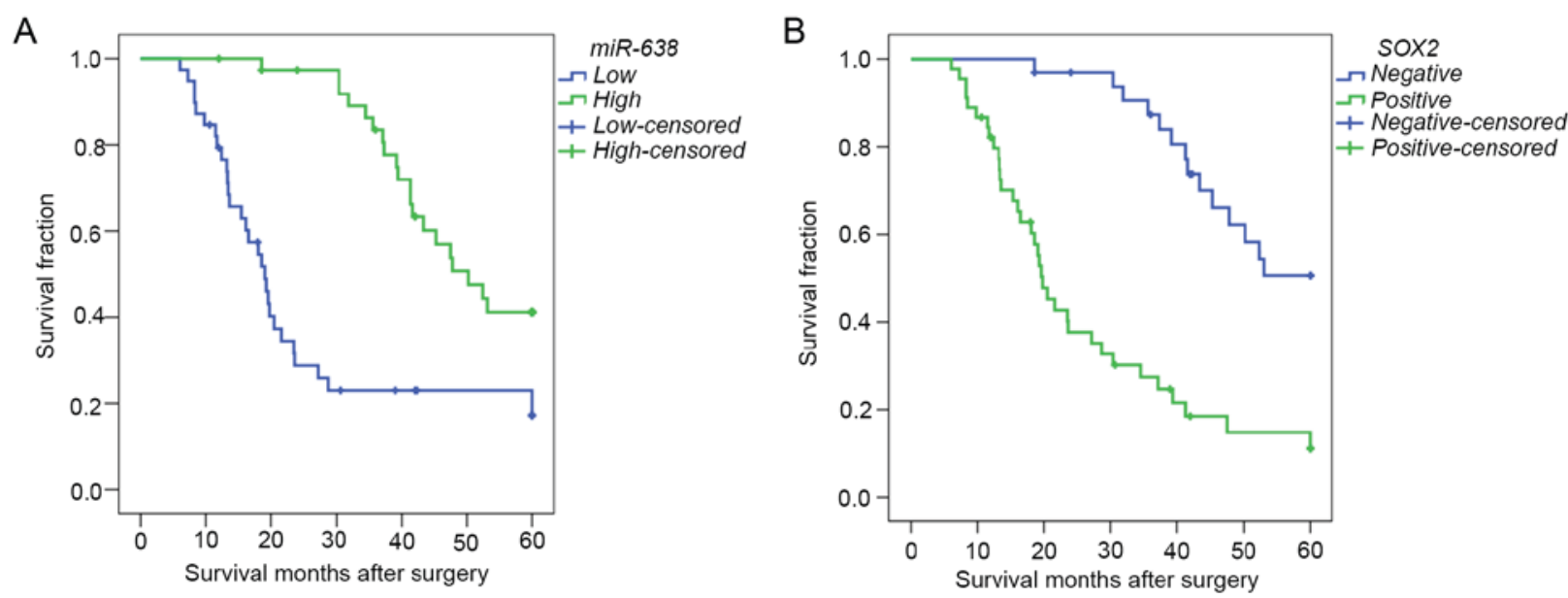

Figure 3. Kaplan-Meier curves for overall survival in patients with HCC. (A) Low miR-638 expression vs. high miR-638 expression and (B) negative SOX2 expression vs. positive SOX2 expression. HCC, hepatocellular carcinoma; miR, microRNA; SOX2, sex-determining region Y-box 2.

diagnosed with HCC exhibit a high mortality rate and a poor prognosis (2-5). In view of this, identifying sensitive and specific biomarkers for early diagnosis, therapy guidance and predicting prognosis is imperative. In the present study, the data indicated that miR-638 may negatively regulate SOX2 expression, and may be associated with advanced TNM stages and portal vascular invasion. The results provided evidence for the regulatory roles of miR-638 and SOX2 in HCC progression, and suggested that miR-638 and SOX2 may be potential biomarkers for predicting the prognosis of patients with HCC.

Dysregulation of miR-638 has been described to be involved in tumorigenesis and tumor progression in various types of human cancer, by targeting specific genes. Notably, the roles of miR-638 in different tumor types remains controversial as it is able to behave either as a tumor suppressive gene or an oncogene. For instance, Tan et al (16) demonstrated that expression of miR-638 reduced cell proliferation and decreased triple-negative breast cancer cell invasion, which in turn contributed to esophageal squamous carcinoma proliferation in vivo (35). Zhao et al (36) also identified that miRNA-638 acts as an anti-oncogene in human gastric cancer cells. By contrast, it has been observed that miR-638 promotes tumorigenesis and tumor development in human colon carcinoma cells and human osteosarcoma cells (37), and contributes to DNA damage in the benzo (a) pyrene-induced human cell transformation (38). Although inconsistent findings regarding miR-638 have been observed in different types of tumors, the role of miR-638 in hepatocarcinogenesis has not been clearly elucidated. Only one previous report demonstrated that underexpression of miRNA-638 promoted the angiogenesis and proliferation of HCC cells by targeting vascular endothelial growth factor (29), indicating that downregulation of miR-638 may serve a vital role in HCC progression. In agreement with this observation, the present study also confirmed that miR-638 expression levels were downregulated in a large number of HCC clinical samples. In addition, it was revealed that the reduced miR-638 expression was negatively correlated with advanced TNM stages and portal vascular invasion. Notably, it was confirmed that patients with tumors with a low expression of miR-638 were significantly more likely to exhibit a poorer overall survival. In line with this, a Cox proportional hazards model, adjusted for the possible prognostic variables, revealed that miR-638 may serve as an independent and favorable prognostic factor for HCC.

SOX 2 is a highly conserved transcriptional regulator, which contributes an important role to the maintenance of embryonic stem cell pluripotency and self-renewal (19). It is well documented that SOX2 is expressed in various tissues and serves an important function in the differentiation and morphogenesis of the esophagus and stomach epithelial $(39,40)$. The roles of SOX2 in these biological processes implicates that it has the potential to modulate the progression of cellular malignant transformation (41). Therefore, numerous studies have demonstrated that SOX2 was aberrantly expressed in a wide variety of solid malignant tumors, including breast, colorectal, prostate and lung cancer (20-23), indicating that SOX2 may act as a key factor in tumorigenesis and tumor development. In addition, previous studies have demonstrated that the overexpression of SOX2 in tumor tissues was associated with a strong invasiveness and a poor prognosis $(42,43)$. Furthermore, SOX2 exhibits a close interaction with numerous miRNAs and, in previous studies, SOX2 activity was attributable to regulation by several miRNAs, including miR-126, miR-429 and miR-625 (44-46). In 2014, Ma et al (27) demonstrated a functional association between miR-638 and SOX2. Their study identified that downregulation of miR-638 promotes colorectal carcinoma cell (CRC) invasion and proliferation by influencing SOX2 expression. It was further demonstrated that miR-638 expression levels were negatively correlated with SOX2 expression, and the invasive and differentiative potential of CRC cells. In the same year, Xia et al (28) reported that the expression levels of miR-638 and SOX2 were inversely associated in non-small-cell lung cancer (NSCLC) tissues. The expression levels of miR-638 in the highly aggressive NSCLC cells were much lower than those in normal lung tissue cells. It was also observed that low miR-638 and high SOX2 expression in NSCLC tissues was significantly associated with tumor size, TNM stage and distant metastasis. Gain and loss of function experiments revealed that miR-638 downregulated SOX2 protein expression in NSCLC cells and inhibited cell invasive potential. Additionally, the regulation of SOX 2 by 
Table IV. Cox regression analysis of overall survival for patients with hepatocellular carcinoma $(\mathrm{n}=78)$.

\begin{tabular}{|c|c|c|c|c|c|c|}
\hline \multirow[b]{2}{*}{ Variable } & \multicolumn{3}{|c|}{ Univariate analysis } & \multicolumn{3}{|c|}{ Multivariate analysis } \\
\hline & HR & $(95 \% \mathrm{CI})$ & P-value & HR & $(95 \% \mathrm{CI})$ & P-value \\
\hline Age, years ( $\geq 57$ vs. $<57)$ & 1.018 & $0.990-1.046$ & 0.216 & & & \\
\hline Sex (female vs. male) & 0.770 & $0.327-1.812$ & 0.549 & & & \\
\hline Tumor size, $\mathrm{cm}(\geq 5$ vs. $<5 \mathrm{~cm})$ & 2.615 & $1.475-4.634$ & $0.001^{\mathrm{b}}$ & 1.560 & $0.907-1.824$ & 0.347 \\
\hline Tumor number ( $\geq 2$ vs. 1 ) & 2.257 & $1.047-4.865$ & $0.038^{\mathrm{a}}$ & & & \\
\hline $\begin{array}{l}\text { Hepatitis B virus } \\
\text { (positive vs. negative) }\end{array}$ & 0.471 & $0.240-0.926$ & $0.029^{\mathrm{a}}$ & & & \\
\hline Cirrhosis (yes vs. no) & 0.813 & $0.365-1.811$ & 0.612 & & & \\
\hline AFP, U/l ( $\geq 400$ vs. $<400)$ & 1.581 & $0.822-3.040$ & 0.170 & & & \\
\hline $\begin{array}{l}\text { Tumor differentiation } \\
\text { (poorly vs. moderately vs. well) }\end{array}$ & 1.407 & $0.975-2.030$ & 0.068 & & & \\
\hline TNM stage (III+IV vs. I+II) & 4.565 & $2.536-8.220$ & $<0.001^{\mathrm{c}}$ & 2.016 & $0.806-5.041$ & 0.134 \\
\hline Portal vascular invasion (yes vs. no) & 5.672 & $3.049-10.549$ & $<0.001^{\mathrm{c}}$ & 3.172 & $1.126-8.931$ & $0.029^{\mathrm{a}}$ \\
\hline Distant metastasis (yes vs. no) & 4.030 & $1.893-8.579$ & $<0.001^{\mathrm{c}}$ & 1.505 & $0.589-3.846$ & 0.394 \\
\hline SOX2 (positive vs. negative) & 4.732 & 2.499-8.959 & $<0.001^{\mathrm{c}}$ & 2.812 & $1.896-3.780$ & $0.013^{\mathrm{a}}$ \\
\hline miR-638 expression (high vs. low) & 0.269 & $0.269-0.149$ & $<0.001^{\mathrm{c}}$ & 0.338 & $0.152-0.751$ & $0.008^{\mathrm{b}}$ \\
\hline
\end{tabular}

${ }^{\mathrm{a}} \mathrm{P}<0.05,{ }^{\mathrm{b}} \mathrm{P}<0.01,{ }^{\mathrm{c}} \mathrm{P}<0.001$. HR, hazard ratio; $\mathrm{CI}$, confidence interval; AFP, $\alpha$-fetoprotein; TNM, Tumor-Node-Metastasis; miR, microRNA; SOX2, sex-determining region Y-box 2.

miR-638 may influence the epithelial-mesenchymal transition in NSCLC cells. An investigation into SOX2 expression and its clinical significance in HCC is therefore important for the management of the disease. The present study confirmed that SOX2 was overexpressed in liver cancer tissues and that SOX2 expression was positively correlated with tumor size, tumor stage and portal vascular invasion, as compared with negative controls. In addition, it was demonstrated that high SOX2 expression levels were associated with a poorer prognosis in patients with $\mathrm{HCC}$, and served as an independent and unfavorable prognostic factor for HCC. The results of the present study supported the hypothesis that SOX2 is a key regulator in tumorigenesis and tumor development, which is in accordance with the results of previous studies on multiple types of cancer $(42,43)$.

In the present retrospective study of patients with HCC, it was observed that miR-638 expression was markedly downregulated and SOX2 presented significantly higher expression in HCC tissue, compared with expression in adjacent non-cancerous controls. It was further validated that reduced miR-638 expression was negatively associated with overexpression of SOX 2 protein in HCC. These observations were, in part, consistent with the conclusion of Zhang et al (30), that miR-638 may influence HCC progression by negatively regulating SOX2 expression. In addition, the present study demonstrated that miR-638 and SOX 2 expression were significantly associated with tumor stage, portal vascular invasion and postoperative survival in patients with HCC. However, the failure to validate the molecular rationale for the involvement of miR-638 and SOX2 in the progression of HCC in vitro is one limitation of the present study. Another limitation is that the present study was retrospective and therefore, the results require further validation with more extensive tests in future prospective studies.

In summary, to the best of our knowledge, the present study was the first to provide evidence regarding the detailed expression pattern and clinical significance of miR-638 and SOX2 in a large number of patients with HCC. Furthermore, the results of the present study suggested that miR-638 may serve an important role in the occurrence and progression of HCC by downregulating SOX 2 expression. Consequently, these proteins may serve as potential novel biomarkers, and may also be beneficial to the currently available HCC indicators for predicting HCC progression and poor prognosis. By identifying the patients who are more likely to have a higher risk of mortality, there is a possibility of implementing a more aggressive therapeutic regimen. Present and future studies regarding miR-638 and SOX2 expression in HCC progression may provide novel insights into the diagnosis and prognosis of this devastating disease.

\section{Acknowledgments}

Not applicable.

\section{Funding}

The present study was funded by the National Natural Science Foundation of Zhejiang Province of China (grant no. LY13H030007).

\section{Availability of data and materials}

The datasets used and/or analyzed during the current study are available from the corresponding author on reasonable request. 


\section{Authors' contributions}

WYe, XC and JL carried out the experiments, and the data collection and interpretation. GF and $\mathrm{YZ}$ participated in the design and coordination of experimental work, and data acquisition. CZ and LC significantly contributed to analysis of data and preparation of the manuscript. WYa designed the study, analyzed and interpreted the data, and drafted the manuscript.

\section{Ethics approval and consent to participate}

Ethical approval was obtained from the Ethics Committee of The First Affiliated Hospital of Wenzhou Medical University (Zhejiang, China), and written informed consent was obtained from all patients.

\section{Consent for publication}

Written informed consent was obtained from all patients.

\section{Competing interests}

The authors declare that they have no competing interests.

\section{References}

1. Torre LA, Bray F, Siegel RL, Ferlay J, Lortet-Tieulent J and Jemal A: Global cancer statistics, 2012. CA Cancer J Clin 65: 87-108, 2015.

2. Bruix J and Sherman M; American Association for the Study of Liver Diseases: Management of hepatocellular carcinoma: An update. Hepatology 53: 1020-1022, 2011.

3. Hsu CY, Liu PH, Hsia CY, Lee YH, Nagaria TS, Lee RC, Lin HC and Huo TI: Surgical resection is better than transarterial chemoembolization for patients with hepatocellular carcinoma beyond the milan criteria: A prognostic nomogram study. Ann Surg Oncol 23: 994-1002, 2016.

4. Tremosini S, Reig M,de Lope CR, Forner A and Bruix J: Treatment of early hepatocellular carcinoma: Towards personalized therapy. Dig Liver Dis 42 (Suppl 3): S242-S248, 2010.

5. Imamura H, Matsuyama Y, Tanaka E, Ohkubo T, Hasegawa K, Miyagawa S, Sugawara Y, Minagawa M, Takayama T, Kawasaki S and Makuuchi M: Risk factors contributing to early and late phase intrahepatic recurrence of hepatocellular carcinoma after hepatectomy. J Hepatol 38: 200-207, 2003.

6. Bartel DP: MicroRNAs: Genomics, biogenesis, mechanism, and function. Cell 116: 281-297, 2004.

7. Lin SL, Chang DC, Ying SY, Leu D and Wu DT: MicroRNA miR-302 inhibits the tumorigenecity of human pluripotent stem cells by coordinate suppression of the CDK 2 and CDK4/6 cell cycle pathways. Cancer Res 70: 9473-9482, 2010.

8. Wang Z, Yin B, Wang B, Ma Z, Liu W and Lv G: MicroRNA-210 promotes proliferation and invasion of peripheral nerve sheath tumor cells targeting EFNA3. Oncol Res 21: 145-154, 2013.

9. Tome M, López-Romero P, Albo C, Sepúlveda JC, Fernández-Gutiérrez B, Dopazo A, Bernad A and González MA: miR-335 orchestrates cell proliferation, migration and differentiation in human mesenchymal stem cells. Cell Death Differ 18: 985-995, 2011.

10. Zhang Y, He X, Liu Y, Ye Y, Zhang H, He P, Zhang Q, Dong L, Liu Y and Dong J: microRNA-320a inhibits tumor invasion by targeting neuropilin 1 and is associated with liver metastasis in colorectal cancer. Oncol Rep 27: 685-694, 2012.

11. Ma D, Tao X, Gao F, Fan C and Wu D: miR-224 functions as an onco-miRNA in hepatocellular carcinoma cells by activating AKT signaling. Oncol Lett 4: 483-488, 2012.

12. Calin GA and Croce CM: MicroRNA signatures in human cancers. Nat Rev Cancer 6: 857-866, 2006.

13. Xu J, Li J, Zheng TH, Bai L and Liu ZJ: MicroRNAs in the occurrence and development of primary hepatocellular carcinoma. Adv Clin Exp Med 25: 971-975, 2016.
14. Zhang J, Fei B, Wang Q, Song M, Yin Y, Zhang B, Ni S, Guo W, Bian Z, Quan C, et al: MicroRNA-638 inhibits cell proliferation, invasion and regulates cell cycle by targeting tetraspanin 1 in human colorectal carcinoma. Oncotarget 5: 12083-12096, 2014.

15. Zhang J, Bian Z, Zhou J, Song M, Liu Z, Feng Y, Zhe L, Zhang B, Yin Y and Huang Z: MicroRNA-638 inhibits cell proliferation by targeting phospholipase D1 in human gastric carcinoma. Protein Cell 6: 680-688, 2015.

16. Tan X, Peng J, Fu Y, An S, Rezaei K, Tabbara S, Teal CB, Man YG, Brem RF and Fu SW: miR-638 mediated regulation of BRCA1 affects DNA repair and sensitivity to UV and cisplatin in triple-negative breast cancer. Breast Cancer Res 16: 435,2014

17. Wang XX, Liu J, Tang YM, Hong L, Zeng Z and Tan GH: MicroRNA-638 inhibits cell proliferation by targeting suppress PIM1 expression in human osteosarcoma. Tumour Biol: Jan 3 , 2017 (Epub ahead of print).

18. Bhattacharya A, Schmitz U, Raatz Y, Schönherr M, Kottek T, Schauer M, Franz S, Saalbach A, Anderegg U, Wolkenhauer O, et al: miR-638 promotes melanoma metastasis and protects melanoma cells from apoptosis and autophagy. Oncotarget 6: 2966-2980, 2015.

19. Fong H, Hohenstein KA and Donovan PJ: Regulation of self-renewal and pluripotency by Sox 2 in human embryonic stem cells. Stem cells 26: 1931-1938, 2008.

20. Leis O, Eguiara A, Lopez-Arribillaga E, Alberdi MJ, Hernandez-Garcia S, Elorriaga K, Pandiella A, Rezola R and Martin AG: Sox2 expression in breast tumours and activation in breast cancer stem cells. Oncogene 31: 1354-1365, 2012.

21. Neumann J, Bahr F, Horst D, Kriegl L, Engel J, Luque RM, Gerhard M, Kirchner T and Jung A: SOX2 expression correlates with lymph-node metastases and distant spread in right-sided colon cancer. BMC Cancer 11: 518, 2011.

22. Jia X, Li X, Xu Y, Zhang S, Mou W, Liu Y, Liu Y, Lv D, Liu CH, Tan X, et al: SOX2 promotes tumorigenesis and increases the anti-apoptotic property of human prostate cancer cell. J Mol Cell Biol 3: 230-238, 2011.

23. Nakatsugawa $M$, Takahashi A, Hirohashi $Y$, Torigoe $T$, Inoda $S$, Murase M, Asanuma H, Tamura Y, Morita R, Michifuri Y, et al: SOX2 is overexpressed in stem-like cells of human lung adenocarcinoma and augments the tumorigenicity. Lab Invest 91: 1796-1804, 2011.

24. Chen Y, Huang Y, Zhu L, Chen M, Huang Y, Zhang J, He S, Li A, Chen R and Zhou J: SOX2 inhibits metastasis in gastric cancer. J Cancer Res Clin Oncol 142: 1221-1230, 2016.

25. Cho YY, Kim DJ, Lee HS, Jeong CH, Cho EJ, Kim MO, Byun S, Lee KY, Yao K, Carper A, et al: Autophagy and cellular senescence mediated by Sox 2 suppress malignancy of cancer cells. PLoS One 8: e57172, 2013.

26. Wang S, Tie J, Wang R, Hu F, Gao L, Wang W, Wang L, Li Z, $\mathrm{Hu}$ S, Tang S, et al: SOX2, a predictor of survival in gastric cancer, inhibits cell proliferation and metastasis by regulating PTEN. Cancer Lett 358: 210-219, 2015.

27. Ma K, Pan X, Fan P, He Y, Gu J, Wang W, Zhang T, Li Z and Luo X: Loss of miR-638 in vitro promotes cell invasion and a mesenchymal-like transition by influencing SOX2 expression in colorectal carcinoma cells. Mol Cancer 13: 118, 2014.

28. Xia Y, Wu Y, Liu B, Wang P and Chen Y: Downregulation of miR-638 promotes invasion and proliferation by regulating SOX2 and induces EMT in NSCLC. FEBS Lett 588: 2238-2245, 2014.

29. Cheng J, Chen Y, Zhao P, Liu X, Dong J, Li J, Huang C, Wu R and LV Y: Downregulation of miRNA-638 promotes angiogenesis and growth of hepatocellular carcinoma by targeting VEGF. Oncotarget 7: 30702-30711, 2016.

30. Zhang Y, Zhang D, Jiang J and Dong L: Loss of miR-638 promotes invasion and epithelial-mesenchymal transition by targeting SOX2 in hepatocellular carcinoma. Oncol Rep 37: 323-332, 2017.

31. Poon RT and Fan ST: Evaluation of the new AJCC/UICC staging system for hepatocellular carcinoma after hepatic resection in Chinese patients. Surg Oncol Clin N Am 12: 35-50, viii, 2003.

32. Li ZS and Li Q: The latest 2010 WHO classification of tumors of digestive system. Zhonghua Bing Li Xue Za Zhi 40: 351-354, 2011 (In Chinese).

33. Flejou JF: WHO Classification of digestive tumors: The fourth edition. Ann Pathol 31 (5 Suppl): S27-S31, 2011.

34. Livak KJ and Schmittgen TD: Analysis of relative gene expression data using real-time quantitative PCR and the 2(-Delta Delta C(T)) method. Methods 25: 402-408, 2001. 
35. Zhang X, Wei J, Zhou L, Zhou C, Shi J, Yuan Q, Yang M and Lin D: A functional BRCA1 coding sequence genetic variant contributes to risk of esophageal squamous cell carcinoma. Carcinogenesis 34: 2309-2313, 2013.

36. Zhao LY, Yao Y, Han J, Yang J, Wang XF, Tong DD, Song TS, Huang $\mathrm{C}$ and Shao Y: miR-638 suppresses cell proliferation in gastric cancer by targeting Sp2. Dig Dis Sci 59: 1743-1753, 2014.

37. Tay Y, Tan SM, Karreth FA, Lieberman J and Pandolfi PP: Characterization of dual PTEN and p53-targeting microRNAs identifies microRNA-638/Dnm2 as a two-hit oncogenic locus. Cell Rep 8: 714-722, 2014.

38. Li D, Wang Q, Liu C, Duan H, Zeng X, Zhang B, Li X, Zhao J, Tang S, Li Z, et al: Aberrant expression of miR-638 contributes to benzo(a)pyrene-induced human cell transformation. Toxicol Sci 125: 382-391, 2012.

39. Wegner M: From head to toes: The multiple facets of Sox proteins. Nucleic Acids Res 27: 1409-1420, 1999.

40. Ishii Y, Rex M, Scotting PJ and Yasugi S: Region-specific expression of chicken Sox 2 in the developing gut and lung epithelium: Regulation by epithelial-mesenchymal interactions. Dev Dyn 213: 464-475, 1998.

41. Liu K, Lin B, Zhao M, Yang X, Chen M, Gao A, Liu F, Que J and Lan X: The multiple roles for Sox 2 in stem cell maintenance and tumorigenesis. Cell Signal 25: 1264-1271, 2013.
42. Honing J, Pavlov KV, Meijer C, Smit JK, Boersma-van Ek W, Karrenbeld A, Burgerhof JG, Kruyt FA and Plukker JT: Loss of CD44 and SOX2 expression is correlated with a poor prognosis in esophageal adenocarcinoma patients. Ann Surg Oncol 21 (Suppl 4): S657-S664, 2014.

43. Lundberg IV, Löfgren Burström A, Edin S, Eklöf V, Öberg Å, Stenling R, Palmqvist R and Wikberg ML: SOX2 expression is regulated by BRAF and contributes to poor patient prognosis in colorectal cancer. PLoS One 9: e101957, 2014.

44. Li J, Du L, Yang Y, Wang C, Liu H, Wang L, Zhang X, Li W, Zheng G and Dong Z: MiR-429 is an independent prognostic factor in colorectal cancer and exerts its anti-apoptotic function by targeting SOX2. Cancer Lett 329: 84-90, 2013.

45. Otsubo T, Akiyama Y, Hashimoto Y, Shimada S, Goto K and Yuasa Y: MicroRNA-126 inhibits SOX2 expression and contributes to gastric carcinogenesis. PLoS One 6: e16617, 2011.

46. Wang Z, Qiao Q, Chen M, Li X, Wang Z, Liu C and Xie Z: miR-625 down-regulation promotes proliferation and invasion in esophageal cancer by targeting Sox2. FEBS Lett 588: 915-921, 2014. 